\title{
Impact of sugar syrup and pollen diet on the bacterial diversity in the gut of indoor-reared bumblebees (Bombus terrestris)
}

\author{
Annelies Billiet ${ }^{1}$, Ivan Meeus ${ }^{1}$, Filip Van Nieuwerburgh ${ }^{2}$, Dieter Deforce ${ }^{2}$, \\ Felix WÄCKERS $^{3}$, Guy SMAGGHE ${ }^{1}$ \\ ${ }^{1}$ Laboratory of Agrozoology, Department of Crop Protection, Faculty of Bioscience Engineering, Ghent University, \\ Coupure Links 653, 9000, Ghent, Belgium \\ ${ }^{2}$ Laboratory of Pharmaceutical Biotechnology, Faculty of Pharmaceutical Sciences, Ghent University, \\ Ottergemsesteenweg 460, 9000, Ghent, Belgium \\ ${ }^{3}$ Biobest NV, Ilse Velden 18, 2260, Westerlo, Belgium
}

Received 16 June 2015 - Revised 15 September 2015 - Accepted 5 October 2015

\begin{abstract}
In this project, we showed the influence of diet on the microbial composition in the gut of indoor-reared bumblebees (Bombus terrestris), using Illumina MiSeq 16S ribosomal RNA (rRNA) sequencing. Three sugar syrups and sterilized pollen from three suppliers were tested. Different effects were observed depending on the developmental stage of the gut microbiota at the start of the dietary treatment. Fructose-rich sugar syrup prevented the colonization of Bifidobacteriaceae in the microbiota of newly emerged bumblebees. This effect was correlated with a lower bacterial community richness and diversity. The pollen diet with the best parameters, regarding the protein content and bumblebee offspring, showed the lowest bacterial richness and diversity. The interaction between diet and the microbiota of bumblebees provides new insights for bumblebee breeders. Diet could be used to modulate the bacterial composition in the gut to improve the health of mass-produced bumblebees used for biological pollination.
\end{abstract}

Bombus terrestris / gut microbiota / pollen / carbohydrate / rearing facilities

\section{INTRODUCTION}

Diet has proven to play an important role in modulating the gut microbiota of mice (Murphy et al. 2010) and humans, over other possible variables such as ethnicity, sanitation, hygiene, geography, or climate (De Filippo et al. 2010). The bacterial colonization dynamics in the gut of insects tend to

Electronic supplementary material The online version of this article (doi:10.1007/s13592-015-0399-1) contains supplementary material, which is available to authorized users.

Corresponding author: G. Smagghe, guy.smagghe@ugent.be

Manuscript editor: James Nieh be different as their guts often present unstable habitats for bacteria (Engel and Moran 2013). Holometabolous insects molt several times during their life. The radical remodeling of the organs during metamorphosis severely disrupts or eliminates attached bacterial populations (Moll et al. 2001). Opportunities for direct transfer of gut symbionts between conspecifics are also rather limited, as in most insects females abandon their eggs after oviposition. Hence, in many insects, gut bacterial communities vary among individuals within a species and are highly influenced by the environment and diet (Engel and Moran 2013). However, some insect species like honeybees and bumblebees show social behavior, which enables direct or indirect transmission of microbiota between and within generations, 
resulting in a more stable gut microbiota (Koch and Schmid-Hempel 2011a; Martinson et al. 2011). Bumblebees of Bombus terrestris harbor a core set of bacteria Neisseriaceae (Snodgrassella), Orbaceae (Gilliamella), Lactobacillaceae, and Bifidobacteriaceae, while other bacteria are found on a more sporadic basis (Koch and SchmidHempel 2011a; Meeus et al. 2015).

To date, several bumblebee species are massreared and used for pollination of crops in greenhouses and in open field (Velthuis and van Doorn 2006). Within this context, bacterial gut symbionts have shown to be important for parasite defense (Koch and Schmid-Hempel 2012; Cariveau et al. 2014), and thus, knowledge about the bacterial composition is also important for rearing facilities. However, it has not yet been studied how food types impact the gut microbiota of bumblebees, and possibly, diet could be an interesting means for a commercial breeder to shift the microbial composition of the bumblebee gut.

The diet of bumblebees consists of pollen and nectar. Pollen is the only source of protein naturally available to bees. The protein content ranges between 2.5 and $61 \%$ of the dry mass of pollen (Roulston and Cane 2000). It also provides important nutrients such as lipids, minerals, sterols, and vitamins (Stanley and Linskens 1974; Roulston and Cane 2000). In rearing facilities, bumblebee colonies are kept indoors and are usually provided with a mix of honeybee-collected pollen (Velthuis and van Doorn 2006). The principal natural carbohydrate source used as energy source for bees is nectar collected from flowers (Goulson 2010). Nectar is dominated by three sugars: glucose, fructose, and sucrose (Percival 1961; Bernardello et al. 2007). The amount and relative concentration of the main sugars vary among plant species (Percival 1961). In rearing facilities, the nectar is replaced by a sugar syrup (Velthuis and van Doorn 2006).

In this project, we investigated the impact of diet on the microbial composition of indoorreared $B$. terrestris, using MiSeq multiplexed $16 \mathrm{~S}$ ribosomal RNA (rRNA) amplicon sequencing. We studied the effect of diet on the gut microbial composition with different kinds of pollen and sugar diets. We fed different diets to newly emerged bumblebees and bumblebees of 4 days old. This setup allowed us to differentiate between the effect of diet on an undeveloped gut microbiota and an already more established microbiota.

\section{MATERIALS AND METHODS}

\subsection{Diet}

The effect of diet was tested using combinations of different pollen diets and sugar syrups. Three pollen diets from different suppliers (further referred to as pollens A, B, and C) were tested. They are all polyfloral, collected by honeybees, and as a standard procedure, sterilized by $15 \mathrm{kGy}$ radiation. The three pollen diets were previously tested for their impact on the number of progeny in bumblebee colonies as shown in Table I. Pollen A had the least favorable properties, while pollen $\mathrm{C}$ proved to have the best properties regarding protein content and drone production. We also prepared three kinds of sugar syrup (50\% $w / w)$ : fructose-rich sugar syrup, sucrose-rich sugar syrup, and Biogluc sugar solution (Biobest), each with its own composition as presented in Table II. The effect of sugar syrup was studied by providing bumblebees with the least favorable pollen diet (pollen A) in combination with Biogluc sugar syrup (pollenA+Biogluc), sucrose-rich sugar syrup (pollenA+sucrose), or fructose-rich sugar syrup (pollenA+fructose). The impact of pollen diet was studied by providing Biogluc sugar syrup, the standard sugar syrup used in rearing facilities, in combination with pollen $A$ (pollenA+Biogluc), pollen B (pollenB+Biogluc), or pollen $\mathrm{C}$ (pollenC+Biogluc).

\subsection{Bumblebees}

The experiment was performed with bumblebees of $B$. terrestris from a continuous mass-rearing program (Biobest, Westerlo, Belgium). The bumblebees were kept under standardized laboratory conditions at $30^{\circ} \mathrm{C}$ and continuous darkness (Mommaerts et al. 2006). All bumblebees used in the following experiments originated from the same queen-right colony, ensuring little variation in microbial composition between individuals (Meeus et al. 2015). This queen-right colony had been fed ad libitum on pollen B and Biogluc sugar syrup.

\subsection{Experimental set-up}

Newly emerged bumblebees, which just completed their metamorphosis, show hardly any microbiota in their 
Table I. Bumblebees were fed three different pollen diets ranging from low pollen quality (pollen A), good pollen quality (pollen B), to very good pollen quality (pollen C), expressed in protein content per dry mass, the average drone production in microcolonies during 50 days, and the average drone weight. This data was obtained from Biobest NV.

\begin{tabular}{llll}
\hline & $\begin{array}{l}\text { Protein content per } \\
\text { dry mass (\%) }\end{array}$ & $\begin{array}{l}\text { Average drone production } \\
\text { in microcolonies in 50 days }\end{array}$ & $\begin{array}{l}\text { Average drone } \\
\text { weight }(\mathrm{g})\end{array}$ \\
\hline Pollen A & $15.00 \pm 0.00$ & $31.50 \pm 1.67 *$ & $0.3300 \pm 0.0117$ \\
Pollen B & $15.81 \pm 0.23$ & $47.41 \pm 1.59^{*}$ & $0.2608 \pm 0.0038^{\circ}$ \\
Pollen C & $23.60 \pm 1.19$ & $55.52 \pm 1.76^{*}$ & $0.3179 \pm 0.0071$ \\
\hline
\end{tabular}

* Drone production during 50 days was significantly different $(P<0.050)$ between the three pollen diets

${ }^{\circ}$ Drones weighed significantly less when fed pollen B. There was no significant difference between the drone weight of pollens A and $\mathrm{C}$

gut, and their bacterial gut community develops in the first 4 days after eclosion (Meeus et al. 2013). Between days 4 and 35 , their bacterial composition and diversity are stable under controlled conditions (Parmentier et al. 2015). To investigate the effect of diet in both developmental stages of the gut microbiota, we set up two groups.

The first group consisted of newly emerged adult bumblebees of less than 1 day old. They were transferred from the queen-right colony into five microcolony boxes with four bumblebees each. We will further use the term "undeveloped microbiota" to describe this group of bumblebees, referring to the condition of their gut microbiota when they started the dietary treatment.

In the second group, we labeled newly emerged adult bumblebees and kept them the first 4 days of their adult life in their queen-right colony fed on pollen $B$ and Biogluc sugar syrup. Spending time in the colony allowed these bumblebees to colonize their gut with a set of bacterial species in accordance with the microbiota of their queen-right colony. At 4-5 days old, the bumblebees were transferred into five microcolonies with four bumblebees each. We will further use the term "established microbiota" to describe this group of bumblebees, referring to the condition of their gut microbiota when they started the dietary treatment.

In both groups, the bumblebees were provided one of the five diets ad libitum during the following 16 days, after which they are sampled.

\subsection{Sample preparation and Illumina sequencing}

Mid- and hindgut were dissected from bumblebees using disinfected dissection material and stored at $-20{ }^{\circ} \mathrm{C}$. The gut was crushed in a $170 \mu \mathrm{L}$ lysozyme solution $(100 \mathrm{mg} / \mathrm{mL})$ and DNA-extraction was performed as described in Meeus et al. (2013). The hypervariable V4 region (254 bp) of the 16S rRNA was amplified in triplicate, using the $515 \mathrm{~F}$ and $806 \mathrm{R}$ primers designed by Caporaso et al. (2011). The 806R primer was bar coded with a different nucleotide for each sample, and both primers contained Illumina adapter sequences necessary for the bridge amplification on the Illumina MiSeq flow cell (Caporaso et al. 2011). Further sample preparation and Illumina sequencing were performed as described in Meeus et al. (2015).

Table II. Bumblebees were fed three kinds of sugar syrup (50\% $w / w)$ : fructose-rich sugar syrup, sucrose-rich sugar syrup, and commercial Biogluc sugar syrup. The sugar composition of each syrup is presented.

\begin{tabular}{lllllll}
\hline & $\begin{array}{l}\text { Sucrose } \\
(\%)\end{array}$ & $\begin{array}{l}\text { Fructose } \\
(\%)\end{array}$ & $\begin{array}{l}\text { Dextrose } \\
(\%)\end{array}$ & $\begin{array}{l}\text { Maltose } \\
(\%)\end{array}$ & $\begin{array}{l}\text { Higher sugar } \\
(\%) \text { s }\end{array}$ & $\begin{array}{l}\text { Preservatives } \\
(\%)\end{array}$ \\
\hline $\begin{array}{l}\text { Fructose } \\
\text { rich }\end{array}$ & 25.00 & 56.25 & 18.75 & 0.00 & 0.00 & 0.00 \\
$\begin{array}{l}\text { Biogluc } \\
\text { Sucrose rich }\end{array}$ & 25.00 & 37.50 & 34.50 & 2.00 & 1.00 & 0.05 \\
\hline
\end{tabular}




\subsection{Data analysis}

Sequences derived from Illumina Miseq were analyzed with the mothur software v. 1.31.1 (Schloss et al. 2009), mainly following the standard operating procedure available on http://www.mothur.org/wiki/ MiSeq SOP, date February 2014. The raw data are publicly available on NCBI's sequence read archive (SRA) under accession number SRP059174. We followed standard operating procedures to optimize the quality of our dataset: At this point, the dataset contained a total of 2,994,069 demultiplexed pairedend reads, representing 311,396 unique sequences. We further removed sequences that contained more than eight homopolymers, sequences that were not complete, chimeras, sequences that only occurred once ("singletons") and sequences that were not correlated with a bacterial taxonomy (e.g., chloroplasts, mitochondria, Archaea, or Eukaryota). This resulted in a total of $2,730,002$ reads whereof 5855 unique sequences. The previous steps clearly retain the majority of the reads (91.2\%). Calculating the distance matrix and clustering with a 0.03 cutoff level on this dataset resulted in 230 operational taxonomic unit (OTU). The taxonomic identity of each OTU was revealed by alignment of each sequence with the Bacterial SILVA SEED database, supplemented with host-specific sequences (i.e., host Apis or Bombus) to improve classification (Newton and Roeselers 2012). In this analysis, we chose to only retain the OTUs that were represented by more than $0.5 \%$ of the reads per sample as we aimed to focus on the core bacteria in the bumblebee gut. This resulted in seven OTUs covering $99.7 \%$ of the reads of the 230 OTUs. The reads of the samples were calculated in percentages, expressing the relative abundance of each OTU. Community richness was calculated using the Chaol estimator (alpha diversity) and community diversity was calculated with the Shannon index (beta diversity).

\subsection{Statistical analysis}

A two-way ANOVA was used to assess the impact of diet (eight samples per diet) and the interaction between diet and the developmental stage of the gut microbiota. The statistical differences in relative abundance of OTUs between diets within each group of bumblebees (four samples per diet) were analyzed using nonparametric overall and pairwise Kruskal-Wallis tests.
The values are reported throughout the study as the means \pm standard error (SE). Differences were deemed significant at $P<0.050$.

\section{RESULTS}

\subsection{Identified OTUs}

The seven OTUs mainly represented the four core bacterial families in $B$. terrestris: Neisseriaceae (Snodgrassella), Orbaceae (Gilliamella), Lactobacillaceae (Lactobacillus bombi and Lactobacillus bombicola), Bifidobacteriaceae (Bombiscardovia coagulans LISPASI-P3 and Bifidobacterium commune). We also found Firmicutes Bacillaceae in nine samples, in very low relative abundances. Taxonomic identification of the OTUs and their closest match in GenBank or EzBioCloud are presented in supplementary information Table S1. The genetic distance of an OTU with its closest bacterial family members is shown for Bifidobacteriaceae (Online Resource Figure S1) and for the Lactobacillaceae and Bacillaceae (Online Resource Figure S2).

\subsection{Impact of diet on the gut microbial composition of $B$. terrestris}

Diet had a significant impact on both the community richness $(P<0.001 ; F=17.716)$ and the community diversity $(P=0.001 ; F=6.093)$ when taking all eight samples per diet in consideration. We also observed a significant interaction between the diet and the developmental stage of the microbial gut community for community richness $(P<0.001 ; F=7.525)$ and a trend toward this interaction for community diversity $(P=0.075$; $F=2.393$ ). As a result of this interaction, effects of diet will be considered within each group of bumblebees.

A Kruskal-Wallis test on the first group (undeveloped microbiota) revealed significant differences between diets in community richness $(P=$ $0.005)$ and community diversity $(P=0.039)$, a consequence of significant differences in the relative abundances of L. bombicola $(P=0.014)$, L. bombi $(P=0.037)$, B. coagulans LISPASI-P3 
( $P=0.033)$ and $B$. commune $(P=0.005)$ between diets.

In the second group (established microbiota), we observed significant effects of diets on the community richness $(P=0.008)$ and community diversity $(P=0.016)$ as a result of differences in the relative abundance of $L$. bombi $(P=0.049)$ and $L$. bombicola $(P=0.005)$. The relative abundance of B. coagulans LISPASI-P3 and B. commune was not significantly altered by diet in this group. One bumblebee died in the diet pollenB+Biogluc, leaving three samples in this diet group. We will further analyze the specific impact of the sugar syrup and also the effect of the pollen diet on the microbial composition in the gut of bumblebees.

\subsection{Impact of sugar syrup}

We studied the effect of the sugar syrup using diets pollen $\mathrm{A}+\mathrm{Biogluc}$, pollen $\mathrm{A}+$ sucrose, and pollenA+fructose. Bumblebees of the group with an undeveloped microbiota (Figure 1) showed a significant lower community richness when fed a fructose-rich sugar syrup (Chao1 $=3.75 \pm 0.48$ ) compared to the sucrose-rich sugar syrup
(Chao1 $=6.00 \pm 0.00 ; P=0.013$ ). This is an immediate consequence of the complete lack of Bifidobacteriaceae (B. coagulans LISPASI-P3 and $B$. commune) in individuals that consumed pollenA+fructose.

The bacterial composition in the gut of bumblebees in the group with an established microbiota (Figure 2) showed no significant differences in community richness, diversity or any bacteria between the three sugar syrups.

\subsection{Impact of pollen diet}

The impact of pollen diet on the gut microbiota of $B$. terrestris was studied using pollenA+ Biogluc, pollenB+Biogluc, and pollenC+Biogluc as diets. Bumblebees from the group with an undeveloped microbiota showed the lowest community richness and community diversity for pollen $\mathrm{C}$; however, there were no significant differences compared to other pollen diets (Figure 3). In bumblebees with an established microbiota, pollen $\mathrm{C}$ led to a complete lack of both $L$. bombicola and $L$. bombi. This resulted in a significantly lower Chaol estimator $(3.75 \pm 0.25 ; P=0.022)$ and Shannon index $(0.81 \pm 0.05 ; P=0.017)$

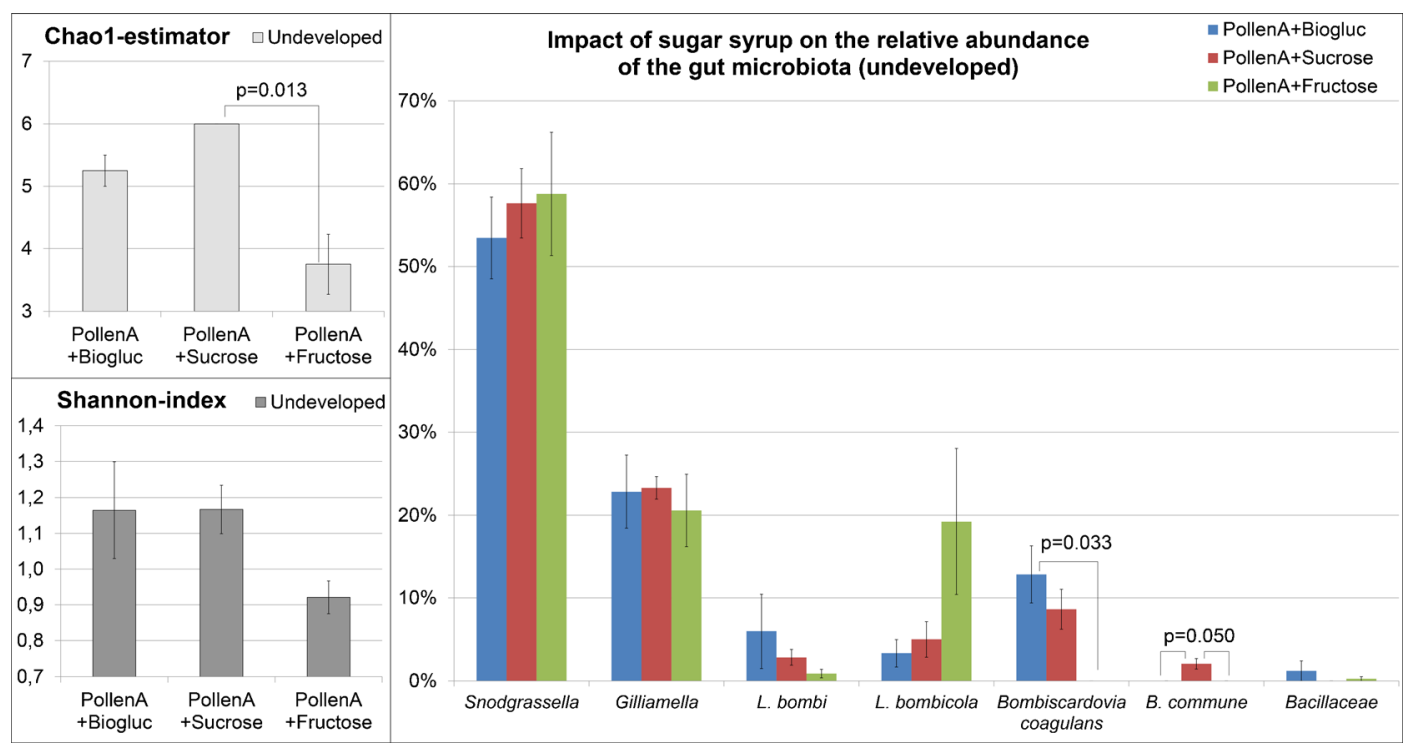

Figure 1. The impact of sugar syrup (Biogluc, sucrose-rich, or fructose-rich) on the community richness (Chao1 estimator), community diversity (Shannon index), and the relative abundance of each OTU for bumblebees that received the specific diet when their gut microbiota was still undeveloped. 


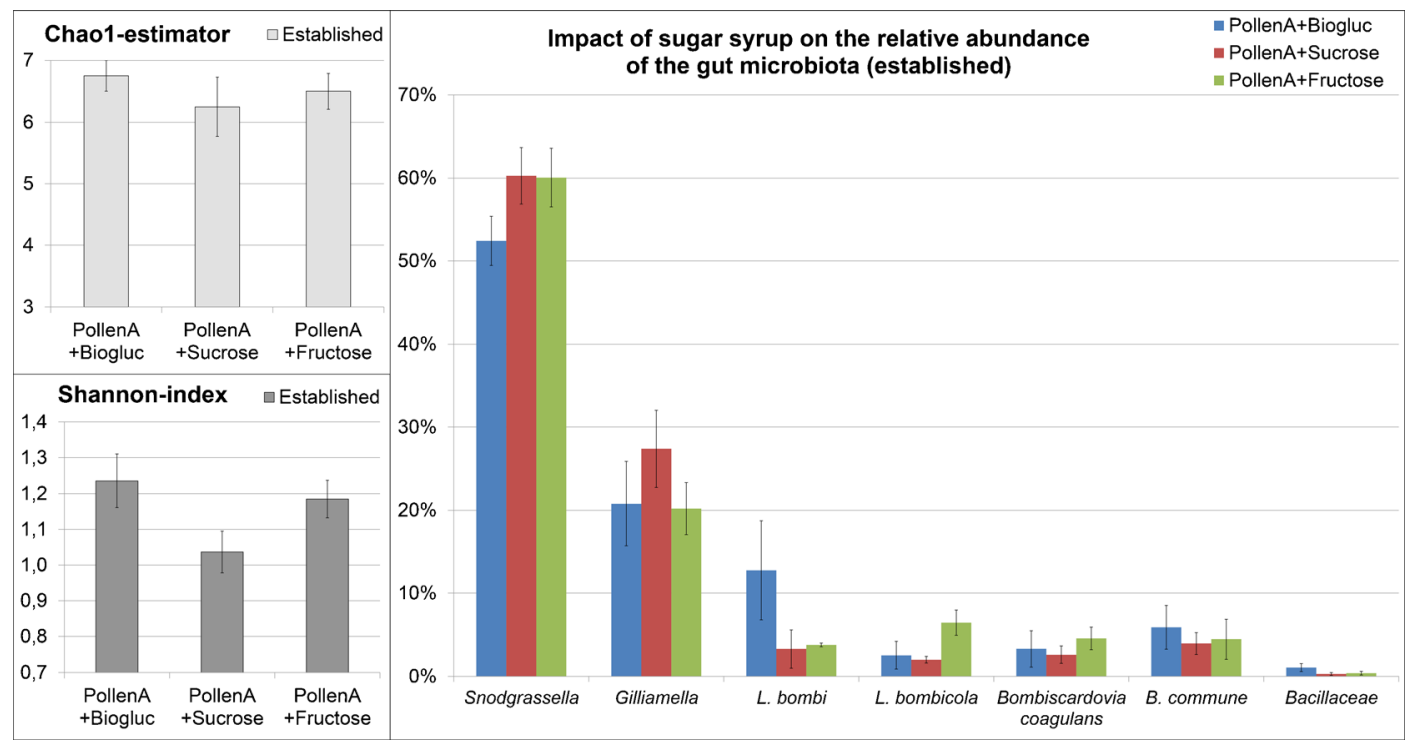

Figure 2. The impact of sugar syrup (Biogluc, sucrose-rich or fructose-rich) on the community richness (Chao1 estimator), community diversity (Shannon index), and the relative abundance of each OTU for bumblebees that received the specific diet when their gut microbiota was already established after 4-5 days.

compared to the pollenA+Biogluc diet $(\mathrm{Chao} 1=$ $6.75 \pm 0.25$; Shannon $=1.24 \pm 0.07$ ). The relative abundance of $L$. bombi was significantly higher $(P=0.037)$ with the pollen A diet $(12.75 \pm 5.98 \%)$ than with pollenC+Biogluc $(0.00 \pm 0.00 \%)$ (Figure 4).

\section{DISCUSSION}

The gut microbiota of indoor-reared bumblebees has been described as consistent and mainly harboring the core bacteria (Meeus et al. 2015). Here, we could confirm their

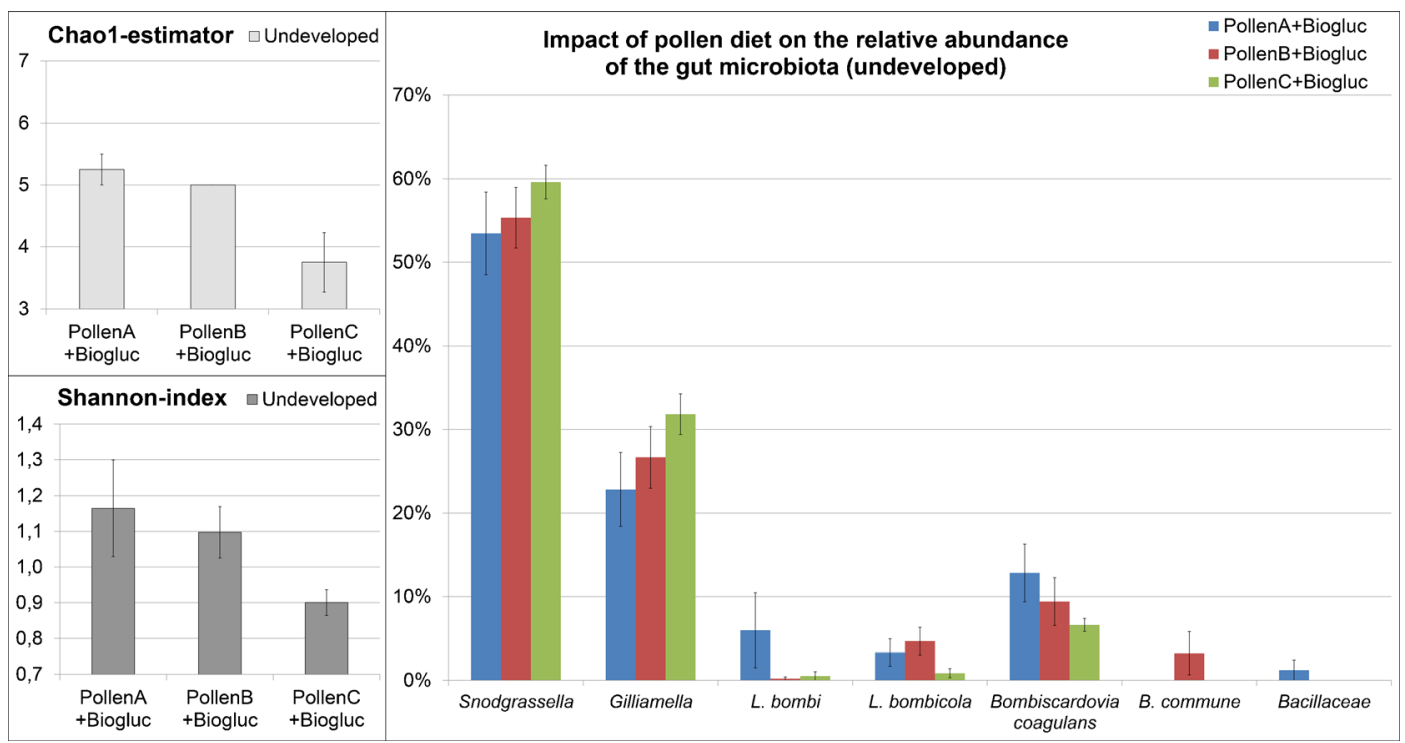

Figure 3. The impact of pollen diet (pollens A, B, or C) on the community richness (Chaol estimator), community diversity (Shannon index), and the relative abundance of each OTU for bumblebees that received the specific diet when their gut microbiota was still undeveloped. 


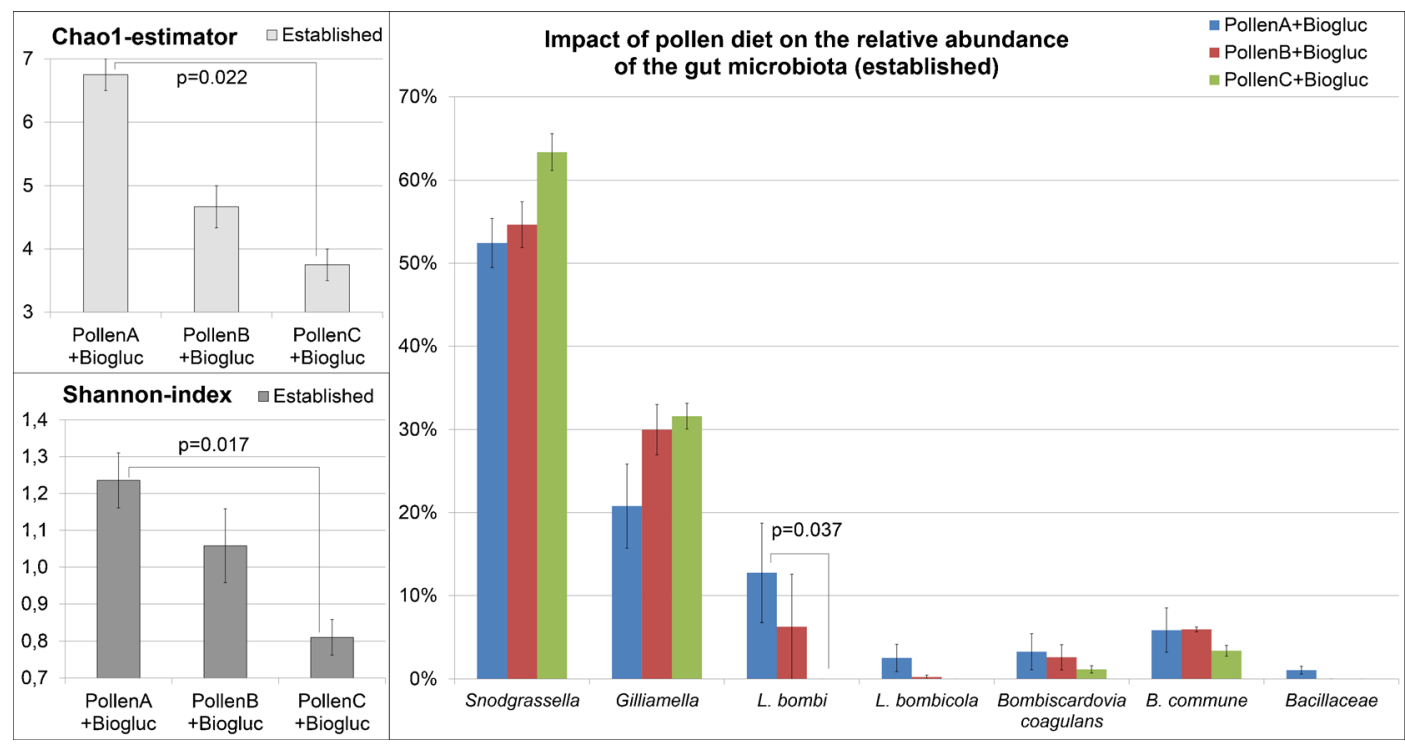

Figure 4. The impact of the pollen diet (pollens A, B, or C) on the community richness (Chaol estimator), community diversity (Shannon index), and the relative abundance of each OTU for bumblebees that received the specific diet when their gut microbiota was already established after 4-5 days.

presence, enabling us to study their relative abundance in relation with the diet of the host. More specifically, we determined whether the pollen diet and sugar syrup influenced the gut microbial diversity and whether the developmental stage of the gut microbiota also played a role. The experiments demonstrated that diet was indeed able to induce some shifts in the relative abundance of the microbial gut composition of indoor-reared bumblebees; however, the effects were rather limited. In this study, we did not investigate if diet was able to affect the absolute community size, which could also change under different dietary conditions.

\subsection{Relative abundances of Snodgrassella and Gilliamella were not altered by diet}

Complete genome sequencing of Gilliamella apicola and Snodgrassella alvi strains, isolated from honeybee guts, suggested that these bacteria contribute in nutrition of the host. Pectate lyase is present and functional in the bacterial genome of some strains of $G$. apicola. This enzyme can digest pectin, which is present in the cell wall of pollen. G. apicola also contains a large number of sugar transporters and sugar utilization pathways, whereas $S$. alvi can only use carboxylates, the metabolites of the sugar metabolism. This shows the complementary capacities of $G$. apicola and S. alvi (Engel et al. 2014; Kwong et al. 2014; Moran 2015). In our study, the relative abundances of the most dominant bacteria Snodgrassella and Gilliamella seemed not significantly susceptible to dietary changes. However, our data does not provide information on strain level. Possibly, diet induced a shift in the strains of Gilliamella and Snodgrassella. Variation in the presence of hundreds of genes has been observed between strains of both G. apicola and S. alvi (Engel et al. 2014; Kwong et al. 2014).

\subsection{Diet affects the relative abundance of Lactobacillaceae and Bifidobacteriaceae}

In contrast to the stability in the relative abundances of Snodgrassella and Gilliamella, the relative abundances of Lactobacillaceae and 
Bifidobacteriaceae were influenced by changes in diet.

\subsubsection{A high fructose concentration can prevent the growth of Bifidobacteriaceae in a developing microbiota}

Providing fructose-rich sugar syrup to newly emerged bumblebee workers resulted in an absence of both $B$. coagulans LISPASI-P3 and $B$. commune in their gut microbiota.

Several Bifidobacteriaceae and Lactobacillaceae were already isolated from the bumblebee gut and taxonomically described, including their carbohydrate fermenting capacities (Killer et al. 2010, 2014; Praet et al. 2015a, b). We summarized the carbohydrate fermenting capacities of Lactobacillaceae and Bifidobacteriaceae occurring in this study in Table III. These characteristics show that $B$. coagulans LISPASI-P3 and two of the four strains of $B$. commune are not able to ferment fructose. On the other hand, Lactobacillaceae are able to ferment fructose, giving them an advantage to colonize the gut.

The microbiota of bumblebees with an established microbiota did harbor Bifidobacteriaceae. This suggests that the Bifidobacteriaceae were obtained during the first 4 days while living in the original queen-right colony which was fed Biogluc sugar syrup and pollen B. Once the Bifidobacteriaceae colonized the gut, they could maintain their prevalence even under high fructose concentrations.

\subsubsection{Pollen diet impacts the diversity of the gut microbiota}

Proteins are important for ovary development (Hoover et al. 2006) and larval development (Tasei and Aupinel 2008; Quezada-Euán et al. 2011). Protein levels can be reflected in the number of progeny, but also the accessibility of proteins and the pollen species composition are important factors which will greatly influence the biomass production (Vanderplanck et al. 2014). In this study, pollen $\mathrm{C}$ had the highest protein content and the highest drone production of the three pollen diets (Table I). However, the microbiota of bumblebees fed on this pollen diet showed the lowest community richness and diversity due to the low abundances of $L$. bombi and L. bombicola in both groups of bumblebees. This observation does not necessarily point toward a correlation between protein levels, high reproduction, and low bacterial diversity. However, our results indicate that high quality in pollen, in terms of biomass production, does not necessarily correlate with a diverse microbiota and can influence the prevalence of Lactobacillaceae .

Earlier studies in honeybees showed that lactic acid bacteria might improve the resistance against Paenibacillus larvae (Forsgren et al. 2010; Vasquez et al. 2012). We speculate that a low abundance of Bifidobacteriaceae and Lactobacillaceae might have negative health consequences when pathogens appear. It is known that the gut microbiota of bees plays a role in the protection against pathogen infection, as bumblebees with a heavily impaired microbiota have been proven to be more susceptible to pathogen intrusion than bumblebees with the typical core gut microbiota (Koch and Schmid-Hempel 2011b). In rearing facilities, the quality of pollen is assessed by the number of drones produced in microcolonies, but this is not a measure for immune competence. Our results show that diet can alter microbial diversity, which might impact the resistance to diseases. Reared bumblebees are used for biological pollination in agriculture in open field and thus also forage on the same flowers as wild bumblebees. Immune competence of reared bumblebees is important as it could affect their susceptibility to get infected by wild bees and this in turn may affect the spread of pathogens (Meeus et al. 2011; Murray et al. 2013; Graystock et al. 2014). However, it remains speculative whether microbial composition can be actively modified to make bees less prone to disease infections, but we believe that efforts should be made into this direction.

\subsection{The choice of sugar syrup and pollen diet as a tool to alter the gut microbiota of reared bumblebees}

The gut microbiota of indoor-reared bumblebees is a subset of the gut microbiota of wild 
Table III. Carbohydrate fermenting capacity of Lactobacillaceae and Bifidobacteriaceae harboring the bumblebee gut in this study.

\begin{tabular}{|c|c|c|c|c|}
\hline Type strains & $\begin{array}{l}\text { Lactobacillus } \\
\text { bombi } \\
\text { BTLCH M1/2 }\end{array}$ & $\begin{array}{l}\text { Lactobacillus } \\
\text { bombicola } \\
\text { LMG } 28288^{\mathrm{T}}\end{array}$ & $\begin{array}{l}\text { Bombiscardovia } \\
\text { coagulans } \\
\text { LISPASI-P3 }\end{array}$ & 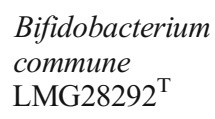 \\
\hline Accession number & KJ078643 & LK054485 & FJ858733 & LK054489 \\
\hline Reference & $\begin{array}{l}\text { Killer et al. } \\
\text { (2014) }\end{array}$ & $\begin{array}{c}\text { Praet et al. } \\
(2015 b)\end{array}$ & $\begin{array}{l}\text { Killer et al. } \\
(2010)\end{array}$ & $\begin{array}{l}\text { Praet et al. } \\
\text { (2015a) }\end{array}$ \\
\hline D-fructose & + & + & - & $+(2 / 4)^{\mathrm{a}}$ \\
\hline (D-)glucose & + & + & + & + \\
\hline Sucrose/D-saccharose & + & - & + & $+(2 / 4)^{\mathrm{a}}$ \\
\hline Maltose & - & ND & - & ND \\
\hline D-maltose & ND & - & ND & - \\
\hline D-adonitol & - & - & - & - \\
\hline Aesculin & + & ND & + & ND \\
\hline Amygdalin & + & + & + & $+(3 / 4)^{\mathrm{a}}$ \\
\hline L-arabinose & + & + & + & - \\
\hline D-arabinose & - & - & - & - \\
\hline Arabitol & ND & ND & - & ND \\
\hline D-arabitol & - & - & ND & - \\
\hline L-arabitol & - & - & ND & - \\
\hline Arbutin & + & + & + & + \\
\hline Cellobiose & + & ND & - & ND \\
\hline D-cellobiose & ND & + & ND & - \\
\hline Dulcitol & - & - & - & - \\
\hline Erythritol & - & - & - & - \\
\hline Esculin ferric citrate & ND & + & ND & + \\
\hline Fucose & ND & ND & - & ND \\
\hline D-fucose & - & - & ND & - \\
\hline L-fucose & - & - & ND & - \\
\hline D-galactose & - & - & - & + \\
\hline Gentiobiose & + & + & + & - \\
\hline Glycerol & - & - & - & - \\
\hline Glycogen & - & - & - & - \\
\hline Inulin & - & - & - & - \\
\hline Inositol & - & - & - & - \\
\hline Lactose & - & ND & ND & ND \\
\hline D-lactose & ND & - & - & - \\
\hline D-lyxose & - & $(+)$ & - & - \\
\hline D-mannitol & - & - & - & - \\
\hline D_mannose & + & + & - & - \\
\hline Melezitose & - & ND & ND & ND \\
\hline D-melezitose & ND & - & - & - \\
\hline Melibiose & + & ND & + & ND \\
\hline D-melibiose & ND & - & ND & + \\
\hline
\end{tabular}


Table III (continued)

\begin{tabular}{|c|c|c|c|c|}
\hline Type strains & $\begin{array}{l}\text { Lactobacillus } \\
\text { bombi } \\
\text { BTLCH M1/2 }\end{array}$ & $\begin{array}{l}\text { Lactobacillus } \\
\text { bombicola } \\
\text { LMG } 28288^{\mathrm{T}}\end{array}$ & $\begin{array}{l}\text { Bombiscardovia } \\
\text { coagulans } \\
\text { LISPASI-P3 }\end{array}$ & 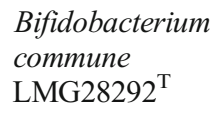 \\
\hline methyl $\beta$-D-xylopyranoside & - & - & - & - \\
\hline $\begin{array}{l}\text { methyl } \alpha \text {-D- } \\
\text { mannopyranoside }\end{array}$ & - & - & - & - \\
\hline $\begin{array}{l}\text { methyl } \alpha \text {-D- } \\
\text { glucopyranoside }\end{array}$ & - & - & + & $+(2 / 4)$ \\
\hline $\mathrm{N}$-acetylgluosamine & $(+)$ & + & - & - \\
\hline Raffinose & + & ND & - & + \\
\hline D-raffinose & ND & - & ND & + \\
\hline L-rhamnose & $(+)$ & - & - & - \\
\hline D-ribose & - & + & ND & + \\
\hline Salicin & + & + & + & + \\
\hline D-sorbitol & - & - & - & - \\
\hline L-sorbose & - & - & - & - \\
\hline Starch & - & - & - & - \\
\hline D-tagatose & - & $(+)$ & - & - \\
\hline Trehalose & $(+)$ & ND & - & ND \\
\hline D-trehalose & ND & + & ND & - \\
\hline Turanose & - & ND & ND & ND \\
\hline D-turanose & ND & - & - & - \\
\hline Xylitol & - & - & - & - \\
\hline D-xylose & + & - & + & - \\
\hline L-xylose & - & - & - & - \\
\hline 2-ketoglucanate & ND & ND & - & ND \\
\hline Potassium 2-ketogluconate & - & - & ND & - \\
\hline 5-ketogluconate & ND & ND & - & ND \\
\hline potassium 5-ketogluconate & - & $(+)$ & ND & $(+)$ \\
\hline (Potassium) gluconate & - & - & - & - \\
\hline
\end{tabular}

+ positive, $(+)$ weakly positive, - negative, $N D$ no data

${ }^{a}$ Number of isolates with a reaction identical to that of the type strain

bumblebees (Meeus et al. 2015). At this point, the effect of a lower community richness or diversity and what an optimal gut microbiota looks like is not known. A good functionality is probably not correlated with a high diversity or richness, but on the presence of certain functional groups of bacteria. As functionalities of the bumblebee microbiota have not yet been completely elucidated, we would encourage to choose diets that either maintain the core gut microbiota or diets that enhance the relative abundance of Bifidobacteriaceae and Lactobacillaceae. Within this context, we would not recommend pollen $\mathrm{C}$ or fructose-rich sugar syrup, which had a negative impact on the relative abundance of Lactobacillaceae and Bifidobacteriaceae. To date, application of probiotics is the most conventional method to manipulate or optimize the gut microbiota in order to ensure higher reproduction (Drillet et al. 2011), better survival (Kaznowski et al. 2005), increase larval growth (Lauzon et al. 2010), or decrease pathogen infection (Evans and Lopez 2004; Forsgren et al. 2010; Kawakami et al. 2010). Our results imply that diet is an important 
parameter to consider when applying a probiotic to enhance the colonization of typical hostspecific bacteria. We speculate that other carbohydrates could also potentially enhance the colonization potential of Bifidobacteriaceae and Lactobacillaceae. Examples are amygdalin, Larabinose, cellobiose, gentiobiose, (D-)melibiose, D-mannose, and salicin, as Lactobacillaceae and/ or Bifidobacteriaceae show positive fermenting capacities for these carbohydrates (see Table III). However, their effect on the gut microbial composition and their nutritional values remain to be studied, as these carbohydrates were not included in the tested diets in this paper.

In conclusion, the composition of the sugar syrup and pollen diet contributed to differences in community richness, community diversity, and the relative abundance of the gut bacteria of indoorreared bumblebees. Rearing facilities should not only monitor the reproduction numbers in bumblebee colonies when choosing their diets, but the impact on the composition of the gut microbiota should also be taken into consideration. In addition, we need further studies to understand the role of the gut microbial composition in protecting bees against pathogens. Our findings provide new insights that the gut microbiota can be modulated through diet types and offers opportunities to shift the gut microbiota of mass-reared bumblebees improving bee health as well as productivity.

\section{ACKNOWLEDGMENTS}

This study was supported by the Institute for the Promotion of Innovation by Science and Technology in Flanders (IWT, Brussels, Belgium) and the Fund for Scientific research (FWO-Flanders, Brussels, Belgium).

Effet de la solution de sucre et le type de pollen sur la diversité bactérienne du tube digestif de bourdons (Bombus terrestris) élevés en colonies au laboratoire

Hymenoptera / Bombus terrestri / microbiote / carbohydrate / pollen / élevage

Der Einfluss von Zuckersyrup und Pollenernährung auf die bakterielle Diversität im Darm von im Freiland aufgezogenen Hummeln (Bombus terrestris)
Bombus terrestris / Darm-Microbiota / Pollen/ Kohlenhydrate / Aufzuchtbedingungen

\section{REFERENCES}

Bernardello, G., Nepi, M., Nicolson, S.W., Pacini, E., Petanidou, T., Thornburg, R.W. (2007) Nectaries and nectar. Springer, Dordrecht

Caporaso, J.G., Lauber, C.L., Walters, W.A., Berg-Lyons, D., Lozupone, C.A., Turnbaugh, P.J., Fierer, N., Knight, R. (2011) Global patterns of 16S rRNA diversity at a depth of millions of sequences per sample. Proc. Natl. Acad. Sci. U. S. A. 108 (Supplement 1), 4516-4522

Cariveau, D.P., Elijah Powell, J., Koch, H., Winfree, R., Moran, N.A. (2014) Variation in gut microbial communities and its association with pathogen infection in wild bumble bees (Bombus). ISME J. 8, 2369-2379

De Filippo, C., Cavalieri, D., Di Paola, M., Ramazzotti, M., Poullet, J.B., Massart, S., Collini, S., Pieraccini, G., Lionetti, P. (2010) Impact of diet in shaping gut microbiota revealed by a comparative study in children from Europe and rural Africa. Proc. Natl. Acad. Sci. U. S. A. 107 (33), 14691-14696

Drillet, G., Rabarimanantsoa, T., Frouel, S., Lamson, J.S., Christensen, A.M., Kim-Tiam, S., Hansen, B.W. (2011) Do inactivated microbial preparations improve life history traits of the copepod Acartia tonsa? Mar. Biotechnol. (NY) 13(5), 831-836

Engel, P., Moran, N.A. (2013) The gut microbiota of insects - diversity in structure and function. FEMS Microbiol. Rev. 37 (5), 699-735

Engel, P., Stepanauskas, R., Moran, N.A. (2014) Hidden diversity in honey bee gut symbionts detected by single-cell genomics. PLoS Genet. 10 (9), e1004596

Evans, J.D., Lopez, D.L. (2004) Bacterial probiotics induce an immune response in the honey bee (Hymenoptera: Apidae ). J. Econ. Entomol. 97 (3), 752-756

Forsgren, E., Olofsson, T.C., Vasquez, A., Fries, I. (2010) Novel lactic acid bacteria inhibiting Paenibacillus larvae in honey bee larvae. Apidologie 41 (1), 99-108

Goulson, D. (2010) Bumblebees: behaviour, ecology and conservation. Oxford University Press, Oxford

Graystock, P., Goulson, D., Hughes, W.O.H. (2014) The relationship between managed bees and the prevalence of parasites in bumblebees. PeerJ 2, e522

Hoover, S.E.R., Higo, H.A., Winston, M.L. (2006) Worker honey bee ovary development: seasonal variation and the influence of larval and adult nutrition. J. Comp. Physiol. B. 176 (1), 55-63

Kawakami, S.-I., Yamada, T., Nakanishi, N., Cai, Y.M. (2010) Effect of probiotics on bacterial flora of various gastrointestinal regions in Holstein calves. J. Anim. Vet. Adv. 9(11), 1556-1559

Kaznowski, A., Szymas, B., Jazdzinska, E., Kazimierczak, M., Paetz, H., Mokracka, J. (2005) The effects of 
probiotic supplementation on the content of intestinal microflora and chemical composition of worker honey bees (Apis mellifera). J. Apic. Res. 44(1), 10-14

Killer, J., Kopecny, J., Mrazek, J., Rada, V., Dubna, S., Marounek, M. (2010) Bifidobacteria in the digestive tract of bumblebees. Anaerobe 16(2), 165-170

Killer, J., Votavová, A., Valterová, I., Vlková, E., Rada, V., Hroncová, Z. (2014) Lactobacillus bombi sp. nov., from the digestive tract of laboratory-reared bumblebee queens (Bombus terrestris). Int. J. Syst. Evol. Microbiol. 64 (Pt 8), 2611-2617

Koch, H., Schmid-Hempel, P. (2011a) Bacterial communities in central European bumblebees: low diversity and high specificity. Microb. Ecol. 62 (1), 121-133

Koch, H., Schmid-Hempel, P. (2011b) Socially transmitted gut microbiota protect bumble bees against an intestinal parasite. Proc. Natl. Acad. Sci. U. S. A. 108(48), 19288-19292

Koch, H., Schmid-Hempel, P. (2012) Gut microbiota instead of host genotype drive the specificity in the interaction of a natural host-parasite system. Ecol. Lett. 15 (10), 1095-1103

Kwong, W.K., Engel, P., Koch, H., Moran, N.A. (2014) Genomics and host specialization of honey bee and bumble bee gut symbionts. Proc. Natl. Acad. Sci. U. S. A. $111(31), 11509-11514$

Lauzon, H.L., Gudmundsdottir, S., Steinarsson, A., Oddgeirsson, M., Petursdottir, S.K., Reynisson, E., Bjornsdottir, R., Gudmundsdottir, B.K. (2010) Effects of bacterial treatment at early stages of Atlantic cod (Gadus morhua L.) on larval survival and development. J. Appl. Microbiol. 108(2), 624-632

Martinson, V.G., Danforth, B.N., Minckley, R.L., Rueppell, O., Tingek, S., Moran, N.A. (2011) A simple and distinctive microbiota associated with honey bees and bumble bees. Mol. Ecol. 20 (3), 619-628

Meeus, I., Brown, M.J.F., de Graaf, D.C., Smagghe, G. (2011) Effects of invasive parasites on bumble bee declines. Conserv. Biol. 25 (4), 662-671

Meeus, I., Mommaerts, V., Billiet, A., Mosallanejad, H., Van de Wiele, T., Wäckers, F., Smagghe, G. (2013) Assessment of mutualism between Bombus terrestris and its microbiota by use of microcolonies. Apidologie 44 (6), 708-719

Meeus, I., Parmentier, L., Billiet, A., Maebe, K., Van Nieuwerburgh, F., Deforce, D., Wäckers, F., Vandamme, P., Smagghe, G. (2015) 16S rRNA amplicon sequencing demonstrates that indoor-reared bumblebees (Bombus terrestris) harbor a core subset of bacteria normally associated with the wild host. PLoS One 10 (4), e 0125152

Moll, R.M., Romoser, W.S., Modrzakowski, M.C., Moncayo, A.C., Lerdthusnee, K. (2001) Meconial peritrophic membranes and the fate of midgut bacteria during mosquito (Diptera: Culicidae) metamorphosis. J. Med. Entomol. 38(1), 29-32
Mommaerts, V., Sterk, G., Smagghe, G. (2006) Hazards and uptake of chitin synthesis inhibitors in bumblebees Bombus terrestris. Pest Manag. Sci. 62 (8), 752-758

Moran, N.A. (2015) Genomics of the honey bee microbiome. Curr. Opin. Insect Sci. 10, 22-28

Murphy, E.F., Cotter, P.D., Healy, S., Marques, T.M., O'Sullivan, O., et al. (2010) Composition and energy harvesting capacity of the gut microbiota: relationship to diet, obesity and time in mouse models. Gut 59 (12), 1635-1642

Murray, T.E., Coffey, M.F., Kehoe, E., Horgan, F.G. (2013) Pathogen prevalence in commercially reared bumble bees and evidence of spillover in conspecific populations. Biol. Conserv. 159, 269-276

Newton, I.L.G., Roeselers, G. (2012) The effect of training set on the classification of honey bee gut microbiota using the Naïve Bayesian Classifier. BMC Microbiol. 12 (1), 1-9

Parmentier, L., Meeus, I., Mosallanejad, H., de Graaf, D., Smagghe, G. (2015) Plasticity in the gut microbial community and uptake of Enterobacteriaceae (Gammaproteobacteria) in Bombus terrestris bumblebees' nests when reared indoors and moved to an outdoor environment. Apidologie. 1-14. doi:10.1007/ s13592-015-0393-7

Percival, M.S. (1961) Types of nectar in angiosperms. New Phytol. 60 (3), 235-281

Praet, J., Meeus, I., Cnockaert, M., Aerts, M., Smagghe, G., Vandamme, P. (2015a) Bifidobacterium commune sp. nov. isolated from the bumble bee gut. Antonie Van Leeuwenhoek 107 (5), 1307-1313

Praet, J., Meeus, I., Cnockaert, M., Houf, K., Smagghe, G., Vandamme, P. (2015b) Novel lactic acid bacteria isolated from the bumble bee gut: Convivina intestini gen. nov., sp. nov., Lactobacillus bombicola sp. nov., and Weissella bombi sp. nov. Antonie Van Leeuwenhoek 107 (5), 1337-1349

Quezada-Euán, J.J.G., López-Velasco, A., Pérez-Balam, J., Moo-Valle, H., Velazquez-Madrazo, A., Paxton, R.J. (2011) Body size differs in workers produced across time and is associated with variation in the quantity and composition of larval food in Nannotrigona perilampoides (Hymenoptera, Meliponini). Insectes Soc. 58(1), 31-38

Roulston, T.H., Cane, J.H. (2000) Pollen nutritional content and digestibility for animals. Plant Syst. Evol. 222 , 187-209

Schloss, P.D., Westcott, S.L., Ryabin, T., Hall, J.R., Hartmann, M., et al. (2009) Introducing mothur: open-source, platform-independent, communitysupported software for describing and comparing microbial communities. Appl. Environ. Microbiol. 75 (23), 7537-7541

Stanley, R.G., Linskens, H.F. (1974) Pollen: biology, biochemistry, management. Springer, Heidelberg

Tasei, J.-N., Aupinel, P. (2008) Nutritive value of 15 single pollens and pollen mixes tested on larvae produced by bumblebee workers (Bombus terrestris, Hymenoptera: Apidae ). Apidologie 39(4), 397-409 
A. Billiet et al.

Vanderplanck, M., Moerman, R., Rasmont, P., Lognay, G., Wathelet, B., Wattiez, R., Michez, D. (2014) How does pollen chemistry impact development and feeding behaviour of polylectic bees? PLoS One 9 (1), e86209

Vasquez, A., Forsgren, E., Fries, I., Paxton, R.J., Flaberg, E., Szekely, L., Olofsson, T.C. (2012) Symbionts as major modulators of insect health: lactic acid bacteria and honeybees. PLoS One 7 (3), e33188

Velthuis, H.H.W., van Doorn, A. (2006) A century of advances in bumblebee domestication and the economic and environmental aspects of its commercialization for pollination. Apidologie 37 (4), 421-451 